\title{
THE PROGNOSIS AND TREATMENT OF DISLOCATED TOTAL HIP ARTHROPLASTIES WITH A 22 мM HEAD
}

\author{
URBAN HEDLUNDH, LENNART SANZÉN, HANS FREDIN
}

From Malmö University Hospital, Sweden

We studied the risk of recurrent dislocation in 121 primary and 39 revision Charnley or Charnley hybrid total hip arthroplasties which had been treated for a primary dislocation between 1979 and 1995. Only 35\% of these hips had no further dislocation or a revision for instability within one year. The rates of survival gradually declined with time or if a second, third or fourth dislocation occurred. The risk of recurrence was greater in men, but was not related to age, diagnosis, time of the first dislocation or whether the index operation had been a primary or a revision procedure.

Operative treatment included 15 reoperations leaving intact components, 50 revisions, and permanent removal of the femoral stem in seven patients. The operation was successful in four patients with reoperations and in 36 who had an exchange procedure within two years. Treatment was successful in 35 of 49 hips in which it was possible to correct a technical error compared with 5 out of 16 hips in which malposition of the components was not seen $(p=0.007)$.

J Bone Joint Surg [Br] 1997;79-B:374-8.

Received 9 August 1996; Accepted after revision 6 December 1996

There are a number of reasons for dislocation after a total hip arthroplasty (THA) including obvious malposition of the components, inadequate tissue tension, worn or loose sockets and implantation in weak or disabled patients. ${ }^{1-8}$ The various prosthetic designs and surgical approaches have specific characteristics and dislocation may occur as a result of two or more suboptimal conditions acting together, ${ }^{2,4}$ and the appropriate treatment is therefore not always obvious.

We investigated the outcome of 160 THAs with a Charnley pattern femoral stem and a $22.25 \mathrm{~mm}$ diameter head which had dislocated, and assessed the results of

U. Hedlundh, MD, PhD, Junior Consultant

L. Sanzén, MD, PhD, Senior Consultant

H. Fredin, MD, PhD, Senior Consultant

Department of Orthopaedics, Malmö University Hospital, S-205 02 Malmö, Sweden.

Correspondence should be sent to Dr. U. Hedlundh.

(c)1997 British Editorial Society of Bone and Joint Surgery 0301-620X/97/37149\$2.00 treatment for recurrent dislocation after follow-up of at least one year.

\section{PATIENTS AND METHODS}

Between 1979 and 1994 we performed 3685 primary THAs and 822 revision arthroplasties. All patients who subsequently had a dislocation were traced by cross-checking the hospital records and the Swedish National Register of Hip Arthroplasty.

Every period of inpatient care was recorded in the hospital register with a WHO ICD-8 code number until 1987 and then with an ICD-9 number. From 1992 there was a separate register using the same classification for all persons seeking emergency care in the city of Malmö. Operative procedures were listed from a different source with a specific code number during the entire period of study. A cross-check was later performed with the Swedish National Register, ${ }^{9,10}$ which, since January 1, 1979, is supposed to receive both the total number of hip operations as well as notes of all revisions performed in every surgical or orthopaedic department in Sweden. Minor procedures such as closed reduction of arthroplasties are inconsistently reported, ${ }^{11}$ but five dislocated hips, not recorded elsewhere, were found through this register. The case notes from 1979 to 1995 were also scrutinised for dislocations by two of the authors, independently. Every documented reduction or reoperation due to dislocation or technical error was carefully analysed. ${ }^{12}$

THAs performed before 1979 were not included, unless they were Charnley prostheses with a first dislocation occurring within the study period; there were ten patients with late dislocations occurring from 5.5 to 17.4 years after the primary operation. Patients undergoing an initial arthroplasty in 1995 were also excluded since their follow-up was for less than one year.

We excluded 32 dislocated prostheses of designs which had either considerably larger heads, had been inserted through a posterior approach, were modular or were specially made for patients with tumours or abnormal anatomy.

Separating the material into primary and revision arthroplasties would have reduced the number of survivors in each group; we were able to show that the type of operation did not appear to affect the survival outcome by either the log-rank test or stepwise regression, and therefore decided 
to pool all dislocations into one group.

The official social-security register in the city of Malmö includes information about all individuals receiving inpatient care at the Malmö University Hospital in addition to their address, date of birth and death. Four patients with incomplete files and postoperative dislocations were not included, since checking showed that they had either been referred to us from distant parts of Sweden or had moved away soon after operation and could not be traced.

We were finally left with 121 primary arthroplasties of which 112 were a standard Charnley and nine were hybrids with uncemented Harris-Galante press-fit or Ceraver threaded cups, and 39 revisions of which 30 were full Charnley and nine were hybrids using Harris-Galante or Ceraver cups. All had a $22.25 \mathrm{~mm}$ diameter femoral head.

Dislocation was defined as a documented positioning of the femoral head outside the acetabular cup. Every primary dislocation was confirmed by a radiograph. In recurrent cases we also accepted a clinical diagnosis made by an orthopaedic surgeon. Sensations of subluxation and dislocation described by the patient and treated without medical help were not included. ${ }^{12}$

Until 1991-2 most of the arthroplasties had been performed with the patient supine through an anterolateral approach with a trochanteric osteotomy. ${ }^{13}$ Since then we have also used a supine, transgluteal anterolateral approach. ${ }^{14}$ This had also been employed in one-third of the patients operated on between 1984 and 1986.

Reoperation was defined as a new operation on a hip and revision as a reoperation with exchange or permanent removal of one or both prosthetic components. The femoral component was removed permanently in seven patients who were mainly wheelchair-bound or bedridden, or were mentally abnormal. All the reoperations and revisions due to recurrent dislocations were performed by one of five experienced surgeons. In each case an analysis of the reasons for dislocation together with a review of the radiographs was placed in the case notes. If no error of positioning was found this was recorded clearly in all but two cases.
We recorded reports of inadequate tissue tension, although exact retrospective review was not possible. Most surgeons applied axial traction to the leg in the anaesthetised patient preoperatively and reported pulling the head out of the socket on to the rim, or producing dislocation by rotation or flexion that would not normally have occurred. A separate examination was made under fluoroscopy in seven patients, and this may also have been performed during earlier reductions, but without any notes in the records.

The position of the components was assessed at the time of revision. The cup position was defined as inadequate if the inclination was outside $30^{\circ}$ to $50^{\circ}$, if it was anteverted more than $20^{\circ}$ or was retroverted. Obvious malrotation of the femoral stem and a suboptimal combination of cup and stem position causing impingement were noted in four cases. Worn or loose components were identified and had usually been diagnosed on the radiographs.

Statistical analysis. Comparisons of any two groups of patients were calculated by the two-tailed Fisher exact test. We performed Kaplan-Meier survival analysis defining failure as a new dislocation or a new operation due to instability. Withdrawals were caused by death or revision due to fracture, infection or aseptic loosening. We calculated $95 \%$ confidence intervals (CI) and used survival and failure-time analysis to compare groups of specific variables, such as gender, age, diagnosis, primary or revision operation and time to first dislocation by Cox proportional-hazard regression.

\section{RESULTS}

Survival analysis showed that only $35 \%$ (CI $27 \%$ to $43 \%$ ) of the primary dislocations had no further dislocation within one year and $30 \%$ (CI 23\% to 38\%) within two years. Second dislocations reduced the further one- and two-year survival rates to $31 \%$ (CI $22 \%$ to $40 \%$ ) and $29 \%$ (CI $20 \%$ to $38 \%$ ), respectively, and these declined gradually with longer follow-up. Further dislocations reduced the survival rate to $13 \%$ (CI $3 \%$ to $22 \%$ ) after four dislocations and a

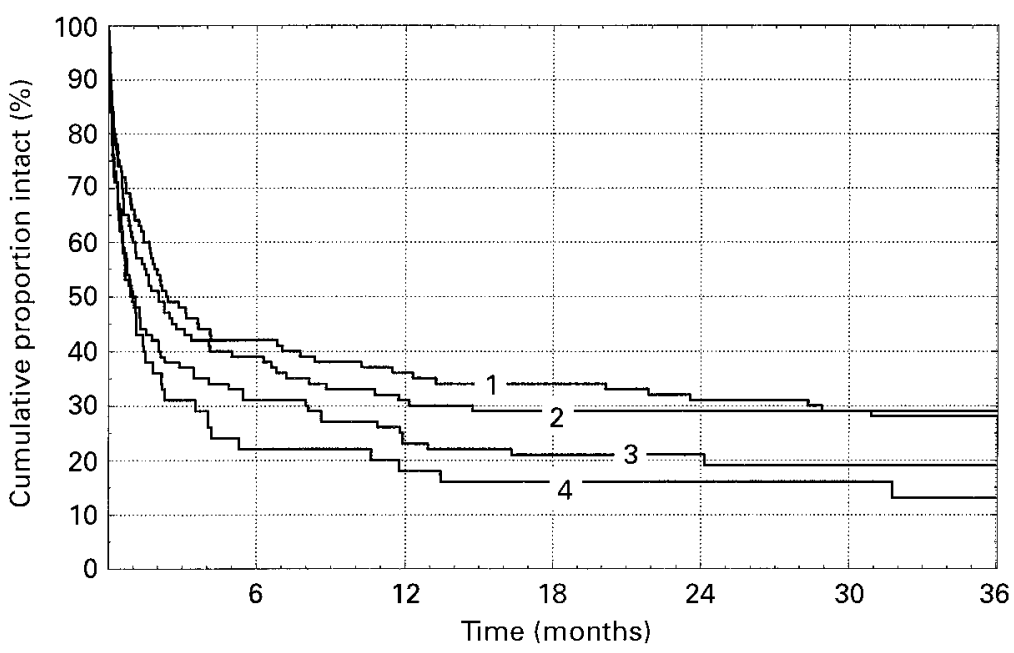

VOL. 79-B, No. 3, MAY 1997
Fig. 1

Analysis of the cumulative number of dislocated THAs that remained stable after one to four dislocations (lines 1, $2,3,4)$ within three years. 
Table I. The risk of redislocation. A risk ratio $>1$ indicates a greater risk for the first mentioned item in the comparison column

\begin{tabular}{|c|c|c|c|c|c|c|}
\hline Variable & Grouping & $\begin{array}{l}\text { Number of patients } \\
\text { with redislocation }\end{array}$ & Comparison & $\begin{array}{l}\text { Risk } \\
\text { ratio }\end{array}$ & $\begin{array}{l}\text { Confidence } \\
\text { interval }\end{array}$ & p value \\
\hline Gender & $\begin{array}{l}\text { Men }(\mathrm{M}) \\
\text { Women }(\mathrm{W})\end{array}$ & $\begin{array}{l}44 / 56 \\
68 / 104\end{array}$ & $\mathrm{M}: \mathrm{W}$ & 1.6 & 1.1 to 2.3 & 0.03 \\
\hline Age in years & $\begin{array}{l}<70(\mathrm{Y}) \\
\geq 70(\mathrm{O})\end{array}$ & $\begin{array}{l}51 / 71 \\
61 / 89\end{array}$ & $\mathrm{Y:O}$ & 1.1 & 0.7 to 1.6 & 0.77 \\
\hline Type of surgery & $\begin{array}{l}\text { Index operation (I) } \\
\text { Revision }(\mathrm{R})\end{array}$ & $\begin{array}{l}83 / 121 \\
29 / 39\end{array}$ & $\mathrm{I}: \mathrm{R}$ & 1.1 & 0.7 to 1.8 & 0.57 \\
\hline Time of first dislocation & $\begin{array}{l}<5 \text { weeks postop }(\mathrm{E}) \\
\geq 5 \text { weeks postop }(\mathrm{L})\end{array}$ & $\begin{array}{l}39 / 57 \\
73 / 103\end{array}$ & $\mathrm{E}: \mathrm{L}$ & 1.0 & 0.7 to 1.6 & 0.86 \\
\hline Diagnosis & $\begin{array}{l}\text { Osteoarthritis (OA) } \\
\text { Rheumatoid disease (RA) } \\
\text { Hip fracture complication (FC) } \\
\text { Other }(\mathrm{OO})\end{array}$ & $\begin{array}{r}50 / 71 \\
21 / 28 \\
35 / 50 \\
6 / 11\end{array}$ & $\begin{array}{l}\text { RA:OA } \\
\text { FC:OA } \\
\text { OO:OA }\end{array}$ & $\begin{array}{l}1.0 \\
1.2 \\
1.3\end{array}$ & $\begin{array}{l}0.6 \text { to } 1.8 \\
0.8 \text { to } 1.9 \\
0.6 \text { to } 3.2\end{array}$ & $\begin{array}{l}0.92 \\
0.48 \\
0.51\end{array}$ \\
\hline
\end{tabular}

Table II. Surgical treatment of recurrent dislocations. Success is defined as no further dislocation within two years of surgery regardless of prosthesis and patient survival

\begin{tabular}{lcc}
\hline Procedure & Number & Successful at two years \\
\hline Reoperations & 15 & 4 \\
Open reduction (including any capsular plasty) & 1 & 0 \\
Reinsertion of displaced greater trochanter & 8 & 0 \\
Extirpation of osteophytes & 1 & 1 \\
Adductor tenotomy & 3 & 2 \\
Cup augmentation according to Olerud & 2 & 1 \\
Revisions & 57 & 36 \\
Exchange of cup & 28 & 20 \\
Exchange of stem & 13 & 7 \\
Exchange of both & 9 & 9 \\
Stem extraction (= Girdlestone) & 7 & Not applicable \\
\hline
\end{tabular}

Table III. Reasons suggested by the surgeons for recurrent dislocations in the cases of reoperation and revisions

\begin{tabular}{lccl}
\hline Causes & Number & $\begin{array}{c}\text { Successful } \\
\text { at two years }\end{array}$ & Stem extraction \\
\hline Cup malposition & 8 & 5 & 1 \\
Stem malposition & 2 & 1 & 0 \\
Worn and/or loose components & 3 & 2 & 0 \\
Impingement (osteophytes, soft tissue, cement) & 6 & 5 & 0 \\
Inadequate tissue tension & 11 & 4 & 1 \\
Combinations of the above & 21 & 18 & 0 \\
Trochanteric pseudarthrosis as single cause* & 10 & 3 & 0 \\
No technical reason & 11 & 2 & 5
\end{tabular}

* trochanteric displacement was determined on radiographs, but was not accepted as a mechanical reason for dislocation

three-year follow-up (Fig. 1). The median survival time after the first dislocation was 72 days.

The risk of a redislocation was not influenced by age, diagnosis, primary or revision surgery or the time to the first postoperative dislocation but was more likely to occur in men than in women (Table I).

Revision for recurrent dislocation was by exchange of the acetabular cup in 28 cases, and by stem exchange in another nine. Trochanteric reattachment was the most common reoperation (Table II). More than one surgical procedure was undertaken in nine patients with an unsuccessful first reoperation or revision.

After elimination of the seven patients treated by permanent extraction of the femoral stem, 40 of 65 patients operated on for an unstable hip arthroplasty did not continue to dislocate. Reoperation was successful in only four of 15 cases as compared with 36 of 50 of the revisions $(\mathrm{p}=0.002)$, when success was defined as no further dislocation within two years (Table II).

The surgeon was unable to determine the cause of the dislocation in 21 cases (Table III). Operations on these patients were successful in five out of 16 cases as compared with 35 of 49 when there was an assumed technical error to correct $(\mathrm{p}=0.005)$.

In the reoperated group 8 of 11 patients returned home after surgery as compared with 38 of 45 revisions. Of these 38 patients, 15 spent an additional one to three weeks in a rehabilitation centre before returning home. Of the seven 
patients undergoing removal of a femoral component, only one returned home and the other six continued in institutional care.

\section{DISCUSSION}

In previous studies the outcome of recurrent dislocations has been difficult to interpret, since they report only short follow-up periods and no defined endpoint for survival of the patient or the prosthesis. ${ }^{2,4,15}$ Dislocations are common in frail and disabled patients who also have a high rate of mortality. ${ }^{8}$ They are also more liable to fracture or infection which may lead to revision. ${ }^{11}$ Survival analysis has not previously been applied to the outcome of dislocations, although it presents obvious advantages.

We included only Charnley or Charnley hybrid arthroplasties. Prostheses of a different design or the use of other approaches may well show other characteristics, ${ }^{16,17}$ but we had too few of these to allow adequate evaluation. Analysis of our own patients only allowed access to complete population data, patient files and radiographs and the experience of a limited number of experienced surgeons.

We did not undertake a further radiological analysis since the surgeons had already scrutinised the radiographs for reasonable causes for dislocation. It is almost impossible to measure the rotational position of the stem on standard radiographs, ${ }^{18}$ and the importance of minor deviations in the placement of the components is questionable. ${ }^{19}$ Our criteria for an adequate position of the cup in this study were narrower than those of previously presented series. $^{20,21}$

Only $35 \%$ of the patients with a postoperative dislocation remained stable, but $31 \%$ of those with a second dislocation and $23 \%$ of those with a third dislocation became stable within one year (Fig. 1). In all cases, almost two out of three will eventually stabilise without further surgery $(35 \%+31 / 100 \times(100-35) \%+23 / 100 \times(100-31) / 100$ $\times(100-35) / 100) \%=65 \%$. This may justify expectant management until a third dislocation has occurred. Both the patient and the surgeon, however, should be prepared for an earlier revision. Early evaluation of the patient's physical and mental status is necessary, with an analysis of the postoperative radiographs and of the mechanism of dislocation seen during reduction under fluoroscopy.

Early postoperative dislocation may be caused by either malpositioned prostheses ${ }^{3}$ or in confused patients with unhealed tissues. The anticipated good outcome in the second group contrasts with the poor outlook in the first. The risk of redislocation, however, was not affected when the definition of the period for early postoperative dislocation was changed from five to two weeks.

Patients with arthroplasties undertaken after united fractures or previous operations on the hip have an increased risk of dislocation, ${ }^{2-5,11,16,17}$ but we found no increased risk of recurrent dislocation in this group. Surprisingly, we found no significant difference in the rate of recurrent dislocation after primary arthroplasty or after revision, although the more extensive surgery in a revision implies diminished biomechanical stabilisation.

The poor results of our reoperations may be explained by an assumption that recurrent dislocation was due to insufficient tissue tension after trochanteric osteotomy and that reinsertion of the trochanter would correct this. Another factor is that in patients without a definite component failure, the surgeon may have hesitated to perform a complete revision and settled for a reoperation. The same five surgeons, however, performed both the reoperations and revisions. Successful revision for recurrent dislocation requires considerable experience and correct understanding of the causes, ${ }^{22}$ and the success rate in our series compares well with that of other reports. ${ }^{23,24}$

Cup augmentation as described by Olerud and Karlström ${ }^{25}$ and Güngör and Hallin ${ }^{26}$ has been found to be helpful although some authors have reported inferior results. ${ }^{27-30}$ We have used the method in only two patients, with no success.

When recurrent dislocation was due to malposition of the prostheses, two-thirds of the revisions remained stable, indicating that many could have been avoided by optimal positioning of the components during the primary procedure.

Five patients had more than one revision but only one of them had eventual success, indicating that there may be a subgroup of patients who are not helped by corrective surgery. The exclusion of neuropathy may be important in all patients with recurrent dislocation.

The chance of an unstable arthroplasty becoming stable after three reductions of a dislocation is very small. Reoperation is expensive and does not always prevent further dislocations. Revision arthroplasty by a competent surgeon is indicated whenever possible; the other choices are to leave the dislocated prosthesis in a displaced position or to remove it.

Financial support was obtained from the Herman Järnhardt foundation and the Lund University funds

No benefits in any form have been received or will be received from a commercial party related directly or indirectly to the subject of this article.

\section{REFERENCES}

1. Carlsson AS, Gentz C-F. Postoperative dislocation in the Charnley and Brunswick total hip arthroplasty. Clin Orthop 1977;125:177-82.

2. Fackler CD, Poss R. Dislocation in total hip arthroplasties. Clin Orthop 1980;151:169-78.

3. Khan MAA, Brakenbury PH, Reynolds ISR. Dislocation following total hip replacement. J Bone Joint Surg [Br] 1981;63-B:214-8.

4. Woo RYG, Morrey BF. Dislocations after total hip arthroplasty. $J$ Bone Joint Surg [Am] 1982;64-A:1295-306.

5. Dorr LD, Wolf AW, Chandler R, Conaty JP. Classification and treatment of dislocations of total hip arthroplasty. Clin Orthop 1983;173:151-8.

6. McCollum DE, Gray WJ. Dislocation after total hip arthroplasty: causes and prevention. Clin Orthop 1990;261:159-70.

7. Garcia-Cimbrelo E, Munuera L. Dislocation in low friction arthroplasty. J Arthroplasty 1992;7:149-55.

8. Hedlundh U, Fredin F. Patient characteristics in dislocations after primary total hip arthroplasty: 60 patients compared with a control group. Acta Orthop Scand 1995;66:225-8. 
9. Ahnfelt L, Herberts P, Malchau H, Andersson GBJ. Prognosis of total hip replacement: a Swedish multicenter study of 4,664 revisions. Acta Orthop Scand 1990;61 Suppl 238:1-26.

10. Malchau H, Herberts P, Ahnfelt L. Prognosis of total hip replacement in Sweden: follow-up of 92675 operations performed 1978-1990. Acta Orthop Scand 1993;64:497-506.

11. Ahnfelt L. Re-opererade totala höftledsplastiker i Sverige under åren 1979-1983. Thesis. University of Göteborg, 1986.

12. Hedlundh $\mathbf{U}$, Ahnfelt $\mathbf{L}$, Fredin $\mathbf{H}$. Incidence of dislocation after hip arthroplasty: comparison of different registration methods in 408 cases. Acta Orthop Scand 1992;63:403-6.

13. Charnley J. Low friction arthroplasty of the hip. Berlin: Springer Verlag, 1979:246.

14. Hardinge K. The direct lateral approach to the hip. J Bone Joint Surg [Br] 1982;64-B:17-9.

15. Eftekhar NS. Dislocation and instability complicating low friction arthroplasty of the hip joint. Clin Orthop 1976;121:120-5.

16. Hedlundh U, Hybbinette $\mathrm{CH}$, Fredin H. Influence of surgical approach on dislocations after Charnley hip arthroplasty. J Arthroplasty 1995;10:609-14.

17. Hedlundh U, Ahnfelt L, Hybbinette CH, Wallinder L, Weckström J, Fredin H. Dislocations and the femoral head size in primary total hip arthroplasty. Clin Orthop 1996;333:226-33.

18. Morrey BF. Instability after total hip arthroplasty. Orthop Clin North Am 1992;23:237-48

19. Pierchon F, Pasquier G, Cotton A, et al.Causes of dislocation of total hip arthroplasty: CT study of component alignment. J Bone Joint Surg [Br] 1994;76-B:45-8.
20. Lewinnek GE, Lewis JL, Tarr R, Compere CL, Zimmerman JR. Dislocations after total hip-replacement arthroplasties. $J$ Bone Joint Surg [Am] 1978;60-A:217-20.

21. Ekelund A, Rydell N, Nilsson OS. Total hip arthroplasty in patients 80 years of age and older. Clin Orthop 1992;281:101-6.

22. Wroblewski BM. Revision surgery in total hip arthroplasty. Springer Verlag, London, 1990.

23. Fraser GA, Wroblewski BM. Revision of the Charnley low-friction arthroplasty for recurrent or irreducible dislocation. J Bone Joint Surg [Br] 1981;63-B:552-5.

24. Daly PJ, Morrey BF. Operative correction of an unstable total hip arthroplasty. J Bone Joint Surg [Am] 1992;74-A:1334-43.

25. Olerud S, Karlström G. Recurrent dislocation after total hip replacement: treatment by fixing an additional sector to the acetabular component. J Bone Joint Surg [Br] 1985;67-B:402-5.

26. Güngör T, Hallin G. Cup re-enforcement for recurrent dislocation after hip replacement. J Bone Joint Surg [Br] 1990;72-B:525.

27. Graham GP, Jenkins AIR, Mintowt-Czyz. Recurrent dislocation following hip replacement. J Bone Joint Surg [Br] 1988;70-B:675.

28. Williamson JB, Galasko CS, Rowley DI. Failure of acetabular augmentation for recurrent dislocation after hip arthroplasty: report of 3 cases. Acta Orthop Scand 1989;60:676-7.

29. Gie GA, Scott TD, Ling RSM. Cup augmentation for recurrent hip replacement dislocation. J Bone Joint Surg [Br] 1989;71-B:338.

30. Cohen B, Field RE, Muirhead-Allwood WF, Rushton N, Scott JE. Problems seen after Olerud acetabular augmentation for recurrent dislocation of total hip arthroplasty. Hip International 1994;4:80-4. 